\title{
Cómo los vídeos musicales cuentan historias: Elementos narrativos en el videoclip de los primeros diez años de la MTV
}

Ana $\mathrm{M}^{\mathrm{a}}$ Caro Oca

Universidad de Sevilla

http://dx.doi.org/10.12795/AdMIRA.2011.01.07

\begin{abstract}
Resumen
El videoclip es un género audiovisual con multitud de características peculiares que lo distinguen de otras formas de comunicación. En este artículo examinaremos el uso que realiza de los mecanismos narrativos, uno de sus aspectos más controvertidos. Utilizando una metodología basada principalmente en las categorias narrativas de Genette, analizaremos cómo cuatro videoclips representativos de los primeros diez años de la MTV cuentan una historia. Particularmente, nos detendremos en estudiar cuestiones como la relación entre música y diégesis, la fragmentación del relato, la construcción de los personajes, la voz narrativa, la focalización y la transtextualidad. Pondremos esto en relación con los aspectos comerciales y mercadotécnicos del formato y reflexionaremos sobre las razones que hacen del videoclip narrativo un producto especialmente bien recibido por los espectadores.
\end{abstract}

\section{Palabras clave}

Videoclip, vídeo musical, televisión musical, MTV, narratividad, relato

\begin{abstract}
Music video is an audiovisual form with plenty of peculiar characteristics that distinguish it from other forms of communication. In this essay we will examine its narrative devices, one of its more controversial aspects. We will use a methodology based mainly on Genette's notions of narrative categories to analyse how four classic music videos from the first ten years of MTV tell a story. Especially, we will study topics such as the relationship between music and diegesis, the fragmentation of story, the construction of characters, narrative voice, focalization and transtextuality. We will also relate this with the commercial strategies surrounding this form and we will reflect on the reasons that make the narrative music video a particularly well received product by the spectators.
\end{abstract}

\section{Keywords}

Videoclip, music video, music television, MTV, narrativity, story 


\section{Introducción y objetivos}

El videoclip es un formato audiovisual promocional con numerosas particularidades que hacen muy interesante su estudio. En este artículo, nuestra intención es abordar el que ha sido calificado como uno de sus aspectos más controvertidos: la narratividad (Viñuela, 2009: 27). Deseamos investigar de qué modo los vídeos musicales cuentan una historia, qué particularidades presentan a la hora de construir diégesis y cómo se relacionan con la música y las convenciones de la actuación musical. Para ello hemos escogido una pequeña muestra conformada por cuatro videoclips de amplia difusión y popularidad que surgieron en los primeros diez años de vida de la televisión musical estadounidense MTV, institución imprescindible para la consolidación y popularización del vídeo musical. Estos vídeos musicales son: THRILLER de Michael Jackson (John Landis, 1983), TAKE ON ME de a-ha (Steve Barron, 1985), LIKE A PRAYER de Madonna (Mary Lambert, 1989) y NOVEMBER RAIN de Guns N'Roses (Andy Morahan, 1992).

\section{Materiales y métodos}

Para realizar este estudio hemos utilizado una metodología habitual en las investigaciones sobre narrativa audiovisual como es el análisis del discurso del texto narrativo según las categorías estructurales establecidas por Genette (tiempo, modo, voz). Tomando esto como base, hemos añadido a dichas variables otros elementos relacionados con lo narrativo, ya sea de los contemplados por el mismo autor (transtextualidad) o por otros estudiosos como Chatman o Casetti y Di Chio (acciones y sucesos, personajes, ambientes). De este modo hemos confeccionado una ficha de análisis que aplicamos a la pequeña muestra seleccionada. Además, en cada videoclip hemos distinguido entre las partes que efectivamente pertenecen al flujo narrativo, a lo que hemos denominado "secuencia narrativa", y aquellas que nos muestran la actuación de los artistas, sea a través del playback de voz o instrumentos, el baile o cualquier otra expresión artística unida intrínsecamente a lo musical, a lo que nos referimos como "secuencia performativa". Asimismo, hemos intentado establecer qué relación se da entre la música y el relato.

Comenzaremos el artículo realizando un breve repaso a la historia del videoclip y, principalmente, a la etapa que comprende el surgimiento y desarrollo de la cadena televisión musical norteamericana MTV. A continuación, pasaremos a recopilar algunos apuntes sobre las particularidades del vídeo musical como discurso, su uso de los elementos narrativos y cuestiones relacionadas con los problemas que puede presentar a la hora de ser analizado como texto audiovisual. Lo siguiente será presentar el corpus y resumir lo resultados del 
análisis realizado con los métodos señalados unas líneas más arriba. En primer lugar lo haremos centrándonos en cada obra de manera individual y, tras esto, pasaremos a establecer un análisis comparativo por grupos de elementos, que serán los siguientes: A. Secuencia performativas y secuencias narrativas: Música y diégesis; B. Configuración de la diégesis y estructuras temporales; C. Personajes, voz y focalización; y D. Transtextualidad. Finalmente, extraeremos las pertinentes conclusiones de este análisis, con las que cerraremos el artículo.

\section{Auge y decadencia de la MTV como televisión musical}

Falta consenso entre los autores que se han acercado al género del videoclip a la hora de fijar sus orígenes. Podemos remitirnos incluso a los comienzos mismos del cine sonoro, cuando grandes estrellas del jazz prestaron sus voces a cortos animados y de imagen real durante la época de entreguerras (Viñuela, 2009: 16-17). Desde ahí hasta los años ochenta, el vídeo musical (o el corto cinematográfico musical) pasó por multitud de formatos y contextos de exhibición pero conservando siempre una característica fundamental: las imágenes siempre se añadían a una canción previamente existente, normalmente adaptándose a su longitud y estructura.

Es a finales de los setenta y en el ámbito del movimiento del New Pop y los programas musicales de la televisión británica donde el videoclip se institucionalizó como método habitual de promoción de singles. Esto estuvo propiciado, a su vez, por la ampliación del tiempo de emisión de televisión en el Reino Unido, que fue cubierto en parte con programas musicales. A principios de los ochenta ocurre algo similar en Estados Unidos, donde se comenzaba a expandir la televisión por cable. El aumento de canales y de horas de programación propició la búsqueda de formas baratas con que rellenar esos espacios vacíos. La cadena MTV surge en este contexto como un modo de reunir ante la pantalla, mediante una programación que consistía en la emisión de un flujo continuo de vídeos musicales, a ese público joven que los anunciantes tenían dificultades para captar por otros medios.

A estas alturas, la industria musical no terminaba de ver los beneficios que podría conllevar el realizar un producto meramente promocional tan caro como un videoclip, principalmente porque consideraba a la televisión musical como poco más que una moda pasajera (Goodwin, 1992: 30 y ss.). Sin embargo, este medio se consolidó y cualquier duda que les quedara a las discográficas sobre su capacidad publicitaria se disipó cuando cintas como el Making of de THRILLER, el emblemático videoclip de Michael Jackson, se convirtieron en productos rentables por sí mismos. Es precisamente durante el año del estreno de THRILLER ${ }^{1}, 1983$, 
cuando MTV extiende su cobertura. Durante esta época, la cadena pasa de emitir videoclips arty y conceptuales de intérpretes principalmente británicos al mayor predominio en su parrilla de los grupos de rock y heavy-metal estadounidenses, quienes prefieren para sus vídeos musicales el aspecto más documentalista de las actuaciones en directo o en estudio. En 1985, MTV pasa a formar parte del conglomerado mediático Viacom y, en el proceso, la cadena se desprende de los que parecían ser dos de sus pilares básicos: la emisión en flujo, no dividida en programas, y la difusión de contenidos dirigidos hacia segmentos concretos de público (narrowcasting). De ahí que a partir de 1986 la MTV amplíe su oferta musical y vaya estableciendo una programación por bloques más tradicional. Comienzan a introducirse secciones centradas en géneros musicales no generalistas, principalmente rap, además del dance o la música alternativa. También se incorporaron diversos programas y series en principio relacionados con la música, más tarde enfocados al público juvenil en general. Estos cambios fueron muy positivos para la cadena, que se convirtió durante el año 1988 en el segundo servicio básico de cable de Estados Unidos con mayor audiencia (Goodwin, 1992: 135-137).

Progresivamente, la MTV ha ido relegando los videoclips a un lugar secundario dentro de una programación cada vez más centrada en otros productos dirigidos al espectador adolescente. Los contenidos musicales se han ido así desplazando a canales secundarios de su mismo conglomerado como MTV2 (Middleton y Beebe, 2007: 1). La MTV de los años 2000 ya no se identifica con lo musical como lo hacía la de los ochenta, y esto se materializa de forma definitiva cuando en 2010 se elimina la leyenda "music television" de su logotipo, dando así por concluida una etapa que había durado 30 años. Esto coincide con un momento de cambios en la industria musical y en los medios de comunicación en general ante la consolidación del uso de Internet. En la actualidad se producen más videoclips que nunca gracias al abaratamiento de los medios de producción y, sobre todo, del de los de promoción. La red se ha revelado como una plataforma excelente para la difusión del vídeo musical ya que, si televisión musical podía ser considerada como una radio con imágenes, las plataformas de vídeo en streaming permiten que el usuario pueda hacer de esa radio una emisora a su medida, con todas las ventajas que eso conlleva.

\section{EI videoclip y los elementos narrativos}

El comienzo de lo que podríamos llamar la edad dorada del videoclip televisivo, aquella que coincide con la popularización de la MTV, coincide además con un cambio de paradigma dentro de la industria musical, que pasa de organizarse alrededor de los objetos materiales 
(elepés, sencillos) para pasar a depender de la creación de derechos sobre la música, de tal forma que éstos se convierten en su principal bien de explotación (Frith, 1988: 57). Esto está íntimamente relacionado con la necesidad de cubrir las demandas del fan con otros productos relacionados con su artista preferido y que complementen las ganancias obtenidas por el producto principal, el disco, como actuaciones, entrevistas, fotografías, pósteres, camisetas y todo tipo de merchandising. En la televisión musical, además de promocionarse estos bienes, lo hacen otros en principio no relacionados con lo musical pero que igualmente pueden verse apoyados por la imagen del artista en cuestión, como películas, ropa, bebidas, cosméticos, etc. (Goodwin, 1992: 45-46).

Situado prácticamente en el centro de esta red de mercadotecnia, el videoclip se configura como un extraño híbrido dentro de las industrias culturales, ya que al mismo tiempo es un instrumento de promoción y contiene el bien que promociona, la canción. E. Ann Kaplan define al vídeo musical como una forma híbrida entre el anuncio y el texto de la cultura pop. Señala que los propios realizadores de videoclips conforman un grupo heterogéneo y que es difícil establecer unos rasgos característicos que distingan a todo videoclip existente. Sin embargo, ese todo sí comparte un rasgo fundamental, y es que en el vídeo musical la canción va a primar sobre lo visual, ya que es la base sobre la que se construye la imagen (1987: 14). Esto y la sujeción a los fines promocionales anteriormente mencionados, va a ser lo que determine el papel que realiza cada uno de los elementos de los que se compone el discurso audiovisual del videoclip.

La estructura de la canción pop es habitualmente cíclica. Alterna sucesivamente sus distintas partes, habitualmente estrofas, puentes y estribillos, lo que dificulta la inserción de una narrativa lineal como acompañamiento a la música. El videoclip, por tanto, va preferir adoptar una forma de narrar acausal y no teleológica (Vernallis, 2004: 17). Sin embargo, eso no significa que sea imposible hallar historias o elementos narrativos a la usanza habitual en los videoclips. Su enorme heterogeneidad y el que en la actualidad no se realicen tan sólo para acompañar canciones pop, sino también géneros menos sujetos a los esquemas musicales cíclicos como la música electrónica, va a permitir que aparezcan en ellos esquemas narrativos lineales.

Pero antes de atender a cómo se manifiestan debemos plantearnos otra pregunta: ¿qué aportan los elementos narrativos al videoclip? A pesar de las dificultades que se plantean para contar una historia en este medio o más bien, para hacerlo a la manera tradicional, Admira no 3 - 2011 
estableciendo relaciones causales y un final definido, lo narrativo ha estado presente desde los inicios del formato, disfrutando de una gran popularidad ${ }^{2}$. Asimismo, el que un videoclip contenga un relato suele estar considerado como seña de prestigio. Para impulsar el lanzamiento de un nuevo álbum de un artista consolidado, la industria tiende a decantarse por la realización de un videoclip "de lujo" que sigue claramente la estela de Thriller, el videoclip por excelencia, y del que hereda muchos de sus rasgos como la apariencia cinematográfica, títulos de crédito incluidos, y un marco narrativo en el que se enmarca la acción musical. Este contenido narrativo puede prolongarse más allá de las fronteras que marca la canción, superando en longitud a las partes musicalizadas y estando por ello más cercano al corto cinematográfico de lo que es habitual.

Una de las claves para explicar esta tendencia puede estar en que la narración de historias teniendo como protagonista al artista en cuestión colabora a crear una mitología que sirve de base para la construcción del estrellato del cantante pop. En el discurso del videoclip narrativo, el cantante pop se establece como un personaje que se sitúa a medio camino entre el mundo real y el mundo discursivo de la ficción, creando lo que Goodwin denomina un texto-estrella ("star-text") (1992: 100). El personaje que aparece en el videoclip no sería un personaje por entero ficcional como el de cualquier película de cine pero tampoco el propio cantante, sino parte de la construcción de éste llevada a cabo a través de los medios de comunicación. Algunos optan por acercarse más abiertamente a lo ficcional, asumiendo una nueva identidad (recordemos a Bowie y sus sucesivas encarnaciones en Ziggy Stardust o Aladdin Sane). Otros rechazan el rol de estrella y desean ser considerados sobre todo músicos, lo que les lleva a tener una presencia mínima en los videoclips que se compensa con la inserción de un contenido que no desvele las intenciones promocionales, más cercano a las artes visuales (Goodwin, 1992: 109-110).

Además de contribuir a construir y consolidar la mitología que rodea al artista, los elementos narrativos que aparecen en el videoclip pueden tener otros fines. Por ejemplo, el matizar el significado de una canción a través de la elaboración una situación ficticia concreta que contextualice sus elementos líricos y abstractos (Goodwin, 1992: 9-10). También ayudan a cumplir uno de los principales objetivos del vídeo musical como instrumento publicitario, que es captar y mantener la atención del espectador. Muchos videoclips incorporan un final con apariencia trascendental, aunque ambiguo, lo que hace que el espectador desee volver a verlo en busca de aquellos detalles que no descubrió o asimiló en el primer visionado y que le podrían ayudar a aclarar su significado (Vernallis, 2004: 24). 
Recopilando lo dicho hasta ahora, podemos afirmar que el videoclip se constituye como un texto plenamente multimedia, determinado por la estructura y cambios de una base musical preestablecida, en el que se dan cita todo tipo de códigos (palabra, música, imagen, danza). Se suma a esto que el vídeo musical suele formar parte de la macronarrativa alrededor de la cual se construye la estrella pop y que ha de cumplir ciertos requisitos, como conformar un flujo que no sólo mantenga la atención del televidente sino que además le haga desear volver a escuchar la canción o ver el vídeo el mayor número de veces posible. Esto hace del discurso del videoclip un objeto de estudio tan complejo como interesante, más aún si tenemos en cuenta su influencia sobre los espectadores jóvenes, en cuya educación audiovisual tienen un peso importante.

\section{Análisis descriptivo del corpus}

Los videoclips en los que vamos a centrar este estudio han sido elegidos teniendo en cuenta las dificultades que supone el estudio de este formato y las limitaciones a las que nos vemos sometidos. Al ser este un artículo de extensión acotada, hemos escogido obras formalmente clásicas en cuanto a cercanas al modo de representación institucional, de modo que presenten las menos dificultades posibles de cara a nuestro estudio. Esto, evidentemente, supondrá un sesgo importante en cuanto a la representatividad de los resultados que obtengamos, pues serán fruto del análisis de un tipo concreto de obra y no del grueso del género. Hemos intentado compensar esta restricción seleccionando vídeos musicales especialmente significativos, con un importante peso en la memoria colectiva y la cultura popular así como

en la definición de la imagen de los artistas cuyos temas ilustran. El que exista un lapso de casi diez años entre el primero y el segundo nos permite, además, observar una notable evolución en los mecanismos de construcción de lo narrativo y su relación con lo musical. En cualquier caso, hemos de resaltar que estas cuatro obras, aunque muy influyentes, sólo nos van a permitir dibujar un esbozo de ciertos rasgos de la variedad narrativa del videoclip que, si por algo se caracteriza, es por una enorme heterogeneidad determinada por las circunstancias de su elaboración y consumo.

\section{A. THRILLER de Michael Jackson (John Landis, 1983)}

El videoclip comienza, después de la pantalla de título, cuando una pareja se queda sin gasolina en medio de un lúgubre bosque. Comienzan a caminar y la soledad da paso a una confesión amorosa. Después de que el chico (Michael Jackson) le pida a su acompañante que se convierta en "su chica" y ésta acepte, menciona que ha de revelarle un secreto. Es 
entonces cuando la luna llena aparece detrás de las nubes y Michael se convierte en un monstruo mientras su novia huye aterrorizada. Cuando está a punto de atraparla, se nos muestra un plano del público gritando en una sala de cine. La primera historia se nos ha revelado como la película que los protagonistas, Michael Jackson y la misma actriz que interpretaba a su novia en esa película, están viendo. Mientras que dentro de la pantalla vestían ropas estilo años cincuenta, ahora aparecen con una vestimenta normal. La chica, asustada, decide abandonar la sala y Michael la acompaña. Es entonces, cuatro minutos después del comienzo del corto, cuando comenzamos a oír la canción. Ambos empiezan a caminar hasta que, mientras atraviesan un cementerio y coincidiendo con las líneas recitadas por Vincent Price que contiene el tema, los cadáveres se alzan de sus tumbas hasta rodearlos. La música se detiene de nuevo para dar paso a otro tipo de melodía, la típica banda sonora de una película de terror y, tras un barrido de la cámara, se nos muestra que Michael Jackson también se ha convertido en zombi para desagradable sorpresa de su chica. Suena de nuevo “Thriller" y Michael, acompañado por los muertos vivientes, ejecuta una coreografía. Tras esta pausa en la acción, la joven huye hasta esconderse en una casa. La música deja paso de nuevo a la banda sonora de terror. Los zombis irrumpen en su refugio, encabezados por Michael Jackson y, cuando éste posa su mano en el hombro de la chica, ella abre los ojos sobresaltada. Al parecer se había quedado dormida y todo ha sido un sueño. Michael se ofrece para acompañarla de vuelta a casa y es entonces cuando vuelve su rostro hacia el espectador, quien puede observar sus ojos de monstruo. La imagen queda congelada y comienzan los títulos de crédito con la canción y la coreografía de nuevo al fondo.

Como vemos, en THRILLER la secuencia narrativa se divide en tres diégesis. Dentro de la segunda diégesis está inserta la única secuencia performativa, pues tanto la primera como la tercera se sitúan fuera de las fronteras de la canción. Estas tres diégesis se van superponiendo a modo de cajas chinas. Cuando está a punto de ocurrir el desenlace de alguna de ellas (por ejemplo, cuando la chica es atacada por el monstruo) cambiamos a otra, que contiene la anterior. Esto ocurre en dos ocasiones, revelándose la primera diégesis como una película y la segunda como un sueño. La interrupción se produce antes de que podamos conocer el desenlace, por lo tanto las tres carecen de él. La última, además, no pasa de la introducción. En cuanto a la configuración del tiempo, en THRILLER es sencilla. Se trata de un relato lineal con sólo algunas pequeñas elipsis al cambiar de localización. Las tres diégesis poseen una estructura parecida: la chica descubre que Michael es un monstruo y él la persigue, hasta que consigue atraparla. Esto da la sensación de que nos encontramos ante un mismo relato que se repite de manera cíclica. La separación de los ambientes coincide con la de esas tres diégesis, 
estableciéndose una clara delimitación en este aspecto. Así la primera ocurre en un bosque; la segunda en el cine, la calle, y la casa abandonada y, por último, una sala de estar sirve de escenario para la tercera.

Sólo existen dos personajes principales, la chica y Michael Jackson, que además está individualizado por el criterio anagráfico (su novia se dirige él mediante su nombre), lo cual es raro en un videoclip, principalmente porque no suelen aparecer diálogos. La focalización es eminentemente externa, aunque con una destacada presencia de planos que reflejan una mirada objetiva irreal (zoom y primeros planos de la cara de la chica), mirada subjetiva (de la chica cuando es atacada) e incluso interpelación (plano final de Michael mirando a cámara). La voz del cantante no se identifica aquí tanto con el narrador como con un diálogo, de hecho así está escenificado pues Michael se dirige a la chica cuando canta.

\section{B. TAKE ON ME de a-ha (Steve Barron, 1985)}

En este videoclip, al contrario de lo que ocurría en THRILLER, tanto la canción como la narración están presentes desde el principio. TAKE ON ME comienza mostrándonos a una chica que se encuentra leyendo un cómic en una cafetería. Para su asombro, el protagonista del tebeo (Morten Harket, cantante del grupo) cobra vida y la invita a introducirse en su interior, a lo que ella acepta. Ante su desaparición, la camarera parece creer que se ha ido sin pagar y, enfadada, coge el cómic, lo arruga y lo tira a la basura. Esto provoca que, dentro del universo de papel, los enemigos derrotados por el protagonista reaparezcan y comiencen a perseguir a la pareja. Él ayuda a escapar a la chica, quien vuelve al mundo real dando a parar en la papelera de la cafetería. para asombro de clientes y dependientes. Preocupada por el destino del chico, corre a su casa con el cómic en las manos. En su cuarto, lee el desenlace de la historia: el chico parece haber muerto dentro de las páginas del tebeo. Sin embargo, la joven lo encuentra en el pasillo de su propia casa, debatiéndose entre su yo de papel y el de carne y hueso. Finalmente este último prevalece y la pareja se abraza, lo que se sobreimpone sobre una imagen del cómic que se titula como el grupo, "a-ha".

En este vídeo musical predomina la secuencia narrativa. La única secuencia performativa que existe está insertada dentro de la narración y se da cuando la chica llega al interior del cómic y el protagonista le muestra su mundo a través de efectos que combinan la imagen animada y la imagen de vídeo. La historia sigue de forma lineal las tres partes de la narración clásica, estando claramente vertebradas por una sucesión de acciones. La acción primera (el chico 
introduce a la chica dentro del cómic) establece la introducción hasta que desemboca en la segunda, origen del conflicto (la camarera tira el cómic a la papelera). Esto lleva a la acción tercera (los enemigos atacan a los chicos). La cuarta (la chica consigue escapar) introduce el desenlace y la quinta (ambos se vuelven a reunir) clausura la historia. Se trata de un relato lineal en el que además apenas hay elipsis, sólo se da una que permite cambiar de escenario (del café a la casa de la chica) y crear suspense previamente al desenlace, pues no sabemos qué ha ocurrido en ese lapso de tiempo con el chico que había intentado hacer frente a los malvados.

Además de los dos protagonistas, consideramos que llegan al estatus de personaje los enemigos y la camarera, que son autores de una acción cada uno. La focalización es eminentemente externa, aunque hay un par de planos que se corresponden con la mirada subjetiva del personaje de la chica (al comienzo, cuando está leyendo el cómic; en el enfrentamiento con los enemigos) y del chico (también en el enfrentamiento con los enemigos). El personaje del chico sólo se identifica con la voz de la canción en el segmento performativo, por lo que no parece adecuado atribuirle el papel de narrador. Cuando ejecuta el playback se dirige hacia ella, lo que confirma que aquí, como en THRILLER, las partes cantadas del tema hacen el papel de diálogo. Pese a ello, la canción tiene poco peso y actúa la mayoría del metraje como banda sonora.

En cuanto a los ambientes, en este cómic existe una fragmentación principal entre el mundo real y el mundo del interior del cómic, separación que además coincide con la introducción (mundo real), nudo (cómic) y desenlace (mundo real) de la historia. Esta fragmentación no es sólo espacial, sino también estética: el interior del tebeo está recreado con técnicas de animación, lo que permite que en la escena final veamos cómo el protagonista se debate entre uno y otro, al oscilar su imagen entre la apariencia animada y la filmada.

\section{LIKE A PRAYER de Madonna (Mary Lambert, 1989)}

En LIKE A PRAYER se nos presenta la historia de una joven (Madonna) que presencia un asesinato por el que es injustamente arrestado el hombre que acudió a ayudar a la víctima. La joven duda en si ir a declarar a la policía o no sobre su inocencia por temor a las posibles represalias de los asesinos. Por ello acude en busca de consuelo a la iglesia, donde reza a la figura de un santo que tiene cierta similitud con el detenido. Agotada, se queda dormida sobre uno de los bancos del templo. En su sueño se suceden varias imágenes relacionadas 
con la iconografía católica, entre ellas una escena en la que el santo toma la forma del hombre inocente. Finalmente decide acudir a la comisaría para contar la verdad sobre los hechos a las autoridades. El vídeo musical se cierra con una caída de telón sobre el escenario de la comisaría y el saludo final hacia la cámara de todos los actores, como si lo que hubiéramos visto fuera una obra de teatro.

La secuencia narrativa vertebra el videoclip, dividiéndose en tres partes. Como ocurría en TAKE ON ME, cada segmento de la historia coincide con un distinto ambiente. El asesinato (acción 1) y detención del chico (suceso 1) ocurren en la calle de lo que parece un suburbio. La huida de la protagonista (acción 2) y la posterior duda y revelación (suceso 2) acontecen en la iglesia. Finalmente, la testificación sucede en la comisaría (acción 3 y conclusión). El relato comienza in media res con la acción 2, lo que contrasta con lo visto en THRILLER y TAKE ON ME, donde el relato era lineal. Se introduce una misma analepsis repetida dos veces, al comienzo del vídeo y dentro del segmento del sueño donde su amplitud es mayor. En ella vemos reflejados la acción 1 y el suceso 1.

Además de estos espacios narrativos, aparecen otros como el exterior de la iglesia, el cielo (espacio del sueño), un campo de cruces ardiendo (espacio performativo) o el escenario teatral del final. Las elipsis dividen principalmente los cambios de espacio (del suburbio a la iglesia y de la iglesia a la comisaria). Dentro del segmento del sueño encontramos también otras cuya amplitud y distancia nos es difícil de determinar, lo que aumenta el significado onírico de las imágenes. De alguna manera esto mimetiza la pérdida de conciencia en un sueño real, donde la percepción del tiempo se anula. En esta secuencia, como señalamos, el videoclip incluye otras imágenes aparentemente inconexas. Comenzaría con la protagonista cayendo desde el cielo y siendo recogida por la directora del coro de góspel, y terminaría con su despertar mientras el coro sale de la iglesia. En el sueño vemos cómo el santo se vuelve hombre y surgen estigmas en las manos de la protagonista. También aparece aquí la segunda analepsis, en la que se nos retrotrae al momento del asesinato, y las dos secuencias performativas, una en que Madonna baila y canta acompañada de un coro góspel y otra que sucede en el campo de cruces, aunque ésta se repite brevemente también al final. Según observamos, existe en este videoclip una triple fragmentación entre el pasado y el presente, el sueño y la realidad y por último, entre ficción y no ficción: la escena final del videoclip está fuera de narración del vídeo, los que saludan al caer el telón son los actores y no los personajes, estableciendo una ruptura con todo lo anterior. 
El personaje principal de este relato es Madonna. Sólo ella focaliza. A través de sus ojos vemos el asesinato, lo que en imagen se refleja en un plano del asesino mirando a cámara que enlaza con el contraplano del rostro de la protagonista. También aparecen planos subjetivos dentro de las imágenes inconexas del sueño, como la de las manos con estigmas. Los demás personajes están caracterizados por su papel frente a acciones y sucesos, como el chico detenido, quien es receptor de sucesos y acciones. Podríamos considerar también como personaje al asesino, por ser el autor del desencadenante de la trama.

En LIKE A PRAYER dicha focalización es mayoritariamente interna. No sólo se nos presenta el sueño de Madonna y la analepsis como parte de sus recuerdos, sino que, además de la imperante mirada objetiva, aparecen los citados planos de mirada subjetiva. Asimismo, nos encontramos con miradas interpelativas en uno de los planos del sueño, donde la cantante se dirige a la cámara para introducir el coro con el verso "let the choir sing", hecho que contribuye a crear cierta extrañeza propia de lo onírico. También hay otra interpelación al final, después de abrirse el telón para que los actores saluden al telespectador, que toma el lugar del público en el teatro.

El relato, por tanto, podría ser calificado de autodiegético. Más aún si tenemos en cuenta que la voz de la canción se puede identificar con la voz de Madonna como narradora de los acontecimientos, quien se dirige a una persona determinada ("I hear your voice"). La ambigüedad de la letra hace que este narratario pueda ser tanto una divinidad como un amante, personas que coinciden en la figura del santo negro. La protagonista sólo canta en los segmentos performativos y algunos determinados puntos de la narración, dirigiéndose en todo caso a cámara o a este posible narratario que es el santo, momentos en los que la letra de la canción no se establecería como narración sino como diálogo.

\section{NOVEMBER RAIN de Guns N'Roses (Andy Morahan, 1992)}

La narración de NOVEMBER RAIN es quizá la más desestructurada de estos videoclips. En ella, a través de las pesadillas que tiene el protagonista (el cantante Axl Rose), se nos narran dos sucesos, su boda y el funeral de su esposa. En este videoclip, al contrario que ocurría en los tres anteriores, la secuencia narrativa y la descriptiva están totalmente separadas desde el comienzo y ni siquiera comparten un espacio, sólo tienen como punto de unión el que los integrantes del grupo aparezcan en ambas.. 
La historia presenta una particularidad importante, ya que se nos muestran sólo dos de sus extremos, el comienzo (la boda) y el fin (el funeral) ${ }^{3}$, entre los cuales hay un importante cambio de estado: la protagonista ha muerto. Nos falta el nudo y no sabemos qué es lo que ha causado su muerte. Se trata de la forma más básica de creación de intriga, recordemos la noción de relato mínimo de Genette ("murió la reina, nadie sabe por qué”) (1998: 16). Podemos intuir que, al estar yuxtapuestos, ambos acontecimientos están relacionados pero no alcanzamos a saber cómo. A esto hay que añadir que los dos puntos de inflexión importantes (muerte y boda) comparten espacio, una misma iglesia.

Por tanto, apenas encontramos dentro de este vídeo musical una acción (el casamiento) y un suceso (la muerte de ella), aderezados con otros sucesos menores de corte anecdótico o alegórico, como el que el guitarrista pierda los anillos o que comience a llover durante el banquete y éste tenga que interrumpirse, todo un presagio de la posterior tragedia. Axl Rose es el personaje principal del vídeo musical, junto con su novia, aunque él adquiere más protagonismo debido a que es el centro de la focalización. Así, por ejemplo, el plano cenital de su despertar nos transmite el desasosiego causado por su pesadilla (mirada objetiva irreal). Los mencionados acontecimientos menores (la pérdida del anillo) permiten que los demás integrantes del grupo ganen protagonismo, aunque no lleguen al estatus de personaje.

NOVEMBER RAIN es, como LIKE A PRAYER, un relato no lineal. Empieza por presentarnos la situación final cuando, suponemos, todo ya ha ocurrido y el protagonista se encuentra emocionalmente deshecho. Encontramos en él hasta tres analepsis. En primer lugar aparecen la de la boda y una breve secuencia que nos muestra a los amigos en un bar, aunque no sabemos cómo se ordenan entre ellas. Finalmente contemplamos la del funeral. El tiempo se manifiesta de manera circular y el videoclip comienza como termina, con el cantante en su cama despertando de la pesadilla. La unión del plano de la novia tirando el ramo con aquel en el que las flores caen sobre su ataúd contribuye igualmente a cerrar ese círculo narrativo. Asimismo, al estar claramente separadas la secuencia performativa y la narrativa, podríamos interpretar que la primera se inserta también dentro de la ficción y el cantante, de este modo, rememora mientras actúa la dolorosa experiencia que ha vivido, situándose así como un narrador autodiegético. 


\section{Comparación de los resultados del análisis por categorías}

\section{A. Secuencia performativas y secuencias narrativas: Música y diégesis}

Comenzaremos comparando el metraje del vídeo y la longitud de la canción. Mientras que en TAKE ON ME y LIKE A PRAYER ambos elementos se corresponden totalmente, en NOVEMBER RAIN y especialmente en THRILLER, el vídeo excede los límites del tema musical. Como señalamos en el análisis, la parte musical de THRILLER se corresponde tan sólo con una de las tres diégesis que aparecen en el videoclip, estando las otras dos no musicalizadas. En NOVEMBER RAIN la diferencia no es tan acusada y lo no musical se limita a una breve introducción y un epílogo a la canción, en los que vemos respectivamente a Axl Rose acostándose y despertándose en su cama.

En cuanto a la presencia de secuencias performativas, ninguno de estos vídeos prescinde de ellas estando, eso sí, claramente delimitadas. Esto se debe no sólo a su propio modo de codificación, que las diferencia claramente del resto de elementos (en ellas los personajes cantan, tocan instrumentos o bailan) sino, principalmente, a que acontecen en un espacio específico y diferenciado del narrativo, como ocurre en NOVEMBER RAIN. En THRILLER y en TAKE ON ME, donde lo narrativo y lo performativo sí llegan a compartir espacio, el avance simultáneo de la narración y la actuación musical parece incompatible. La acción queda en pausa cuando el baile o actuación gana en presencia. En THRILLER podríamos prescindir de la secuencia performativa por completo y la narración quedaría prácticamente intacta. En TAKE ON ME es precisamente la irrupción de los enemigos del protagonista, una acción que hace avanzar la trama, lo que interrumpe la secuencia performativa. En LIKE A PRAYER, el espacio performativo y el narrativo están tanto compartidos como separados. Existen dos secuencias performativas y una se desarrolla en un espacio diferenciado, un campo de cruces ardiendo, y otra, la del coro góspel, forma parte del sueño de la protagonista, por lo que está insertada en la diégesis. Al igual que sucede en TAKE ON ME y THRILLER, esta última sólo se desarrolla cuando la narración se detiene.

La forma de la actuación parece estar tipificada según se trate de un conjunto musical o de un solo intérprete. Tanto en el vídeo de a-ha como en el de Guns N'Roses aparecen todos los miembros del grupo tocando sus respectivos instrumentos, de tal forma que la música es diegética en las secuencias performativas. Sin embargo, en las narrativas el interés se centra, de entre todos los miembros del conjunto, sobre la figura del cantante, quien se erige como protagonista de la historia, teniendo el resto de integrantes un papel pequeño (NOVEMBER 
RAIN) o ningún papel (TAKE ON ME). En los vídeos musicales de solistas, en nuestro caso THRILLER y LIKE A PRAYER, aunque la voz es diegética (durante todo el metraje en THRILLER y en algunos momentos en LIKE A PRAYER) la música instrumental es extradiegética, no aparece en pantalla ningún mecanismo que justifique el sonido.

\section{B. Configuración de la diégesis y estructuras temporales}

Junto con la ruptura establecida entre las secuencias performativas y los narrativas que acabamos de señalar, en los cuatro videoclips se establece una fragmentación de universos. En THRILLER tenemos una diégesis que se descubre como la película que ven los protagonistas y otra que se desvela como el sueño de la chica. En TAKE ON ME encontramos la división entre el universo real y el interior del cómic. Por último, la oposición entre sueño y realidad también vertebra LIKE A PRAYER y NOVEMBER RAIN.

Estos videoclips están organizados según diversas configuraciones diegéticas, desde la estructura clásica y lineal de TAKE ON ME, pasando por la de cajas chicas de THRILLER y su esquema circular o la no linealidad que observamos en LIKE A PRAYER o NOVEMBER RAIN, que además coinciden en introducir una analepsis a través del sueño del protagonista. En estos dos últimos, los saltos temporales son además acrónicos. No sabemos exactamente cuánto tiempo ha pasado de uno a otro extremo de la historia, ya que no aparecen marcas que nos lo indiquen. En LIKE A PRAYER la luz del día en la escena de la comisaria nos hace intuir que toda la acción sucede en el espacio de una noche. Pero en NOVEMBER RAIN es imposible conocer la duración y el orden que corresponde a las secuencias presentadas, excepto que la boda fue antes que el entierro de la chica.

Al respecto de la fragmentación temporal, como ya hemos mencionado, tanto LIKE A PRAYER como NOVEMBER RAIN están fracturados y comienzan in media res. Ambos coinciden en presentar el flashback a través del sueño de los protagonistas. Esta fragmentación propicia la introducción de mecanismos de intriga clásicos. En NOVEMBER RAIN vemos cómo Axl Rose se droga antes de acostarse. El ruido de tormenta hace presagiar alguna catástrofe. En LIKE A PRAYER, cuando Madonna entra en la iglesia, se nos muestra una versión corta de la analepsis que se desarrollará más tarde, con la que se nos pone en someros antecedentes de lo que ha ocurrido. De esta manera, el espectador puede establecer un enlace entre la figura del santo y la del chico negro, aunque no sepa exactamente quién es ni qué relación existe entre él y la protagonista. 
En estos cuatro vídeos musicales, las elipsis no son muy abundantes y se utilizan sobre todo para vertebrar los cambios de escenario. Sólo en NOVEMBER RAIN existe esa falta de causalidad característica a la que aludía Vernallis (2004: 17), puesto que precisamente una gran elipsis elimina lo que podría ser el nudo de la historia y nos impide saber las causas de la muerte de la novia.

No sólo hay rupturas dentro del discurso de la ficción, sino también en la frontera que separa a éste de la no ficción. En LIKE A PRAYER, como en THRILLER, se destruye la cuarta pared mediante la mirada interpelativa. En THRILLER esta mirada cierra la narración, mostrando al espectador los ojos de monstruo de Michael Jackson y dándole una pista sobre lo que va a ocurrir a continuación: la chica se cree por fin a salvo pero nosotros sabemos que sigue en peligro, continuándose el ciclo narrativo de modo inferencial. En LIKE A PRAYER se va aún más allá en cuanto a la destrucción de la ilusión de ficción, ya que al final del vídeo los actores saludan al alzarse el telón que había caído poniendo fin al relato ${ }^{4}$.

\section{Personajes, voz y focalización}

Como parece lógico por la escasez de tiempo, en estos videoclips no encontramos numerosos personajes. El rasgo más destacado en lo referente a esta categoría es, como ya dijimos, que las narraciones están protagonizadas por los respectivos cantantes. Esto es algo enormemente relevante si tenemos en cuenta el rol que juegan los videoclips en la construcción del textoestrella al que aludíamos en apartados anteriores. Se nos sitúa en un modo muy cercano a la hiperrealidad a través de la construcción de una ficción donde los artistas se interpretan a sí mismos $^{5}$ en situaciones que nunca han tenido lugar, distintas a las habituales actuaciones musicales. Esto está reforzado por la introducción de detalles que mimetizan la vida real del cantante. Por ejemplo, en NOVEMBER RAIN, la novia de Axl Rose es precisamente su pareja de aquella época, Stephanie Seymour. También puede incorporarse dentro del discurso de ficción una figura en representación del público objetivo: el fan. En THRILLER y TAKE ON ME, el papel de la chica lo interpretan actrices no conocidas y sin rasgos demasiado particulares, lo que facilita la identificación del televidente con ellas a nivel metatextual (Mercer, 1993: 33).

La construcción del personaje se acerca a lo que el artista transmite a través de otros medios, ya sea su propia música o el merchandising. De este modo, a través de los vídeos musicales analizados se nos muestra que Michael Jackson es un joven normal, amante de las películas de terror y las bromas, que, a pesar de todo, se preocupa por su novia ${ }^{6}$; Morten Harket, 
cantante de a-ha, se alza como un héroe valiente y romántico, que no duda en arriesgar su vida para proteger a su amada; Madonna es una chica de barrio que, a pesar de su imagen algo agresiva y pasota, finalmente se inclina por el lado del bien y la justicia; y por último, Axl Rose es un hombre sumido en la desgracia pero que cuenta con el apoyo incondicional de sus compañeros de grupo y amigos.

La voz narrativa en el vídeo musical resulta difícil de analizar, pues se ve impregnada por las convenciones y usos de la música pop. A este respecto podemos considerar la canción de varias maneras: como una mera banda sonora que ilustra la imagen, como la voz dialógica del cantante dentro de la historia o como una voz narrativa. Estas opciones no son excluyentes entre sí, pues dentro de un mismo vídeo musical la letra de la canción y la voz del cantante pueden actuar de todas estas formas. En TAKE ON ME, por ejemplo, predomina su papel de banda sonora aunque en algunos segmentos del vídeo se usa como diálogo. En THRILLER, sin embargo, todas las palabras de Michael Jackson se dirigen a su acompañante. Un ejemplo de la canción como voz narrativa lo tendríamos en LIKE A PRAYER y NOVEMBER RAIN. No existe un interlocutor claro en imagen hacia el que se proyecten las palabras del cantante. En NOVEMBER RAIN, parece que las palabras de Axl Rose son una reflexión tras la muerte de su chica ("nothing lasts forever", dice la letra). La interpretación de lo que ocurre en LIKE A PRAYER es más complicada, puesto que la canción puede tomarse como un diálogo con la divinidad, con su personificación, el santo-amante, e incluso con el espectador, ya que Madonna llega a dirigir sus versos hacia la cámara.

En este sentido, tal y como Goodwin (1992: 75) ha señalado, existe en el videoclip un rasgo fundamental que lo diferencia de otras formas de narración y está muy relacionado con su naturaleza musical: la canción pop siempre implica a un narrador oral (el cantante), sea éste una entidad real o un personaje creado en el texto-estrella. Cuando el cantante cuenta una historia generalmente se convierte al mismo tiempo en un personaje de la narración y en el narrador. El problema que esto supone para una forma audiovisual como el videoclip es que habitualmente no tendremos claro si nos encontramos ante un cantante narrador, un personaje narrador o ambos, puesto que el cantante pop se sitúa en un territorio ambiguo entre la ficción y la no ficción. Por esto hemos de tener también presente que, cuando el cantante se dirige a cámara, puede no tratarse de una ruptura con la representación ficcional, sino de una convención más de la actuación musical en la que el cantante narrador se dirige a su público al contar la historia. En THRILLER, es evidente que en el plano donde Michael Jackson nos dirige su mirada interpelativa, al final del vídeo, está rompiendo con la cuarta pared, pues nos 
encontramos fuera de los límites de la canción. Sin embargo, cuando en LIKE A PRAYER Madonna mira a cámara y canta "let the choir sing" se trata de un gesto más ambiguo. El que la diégesis se ambiente dentro de un sueño y el plano esté situado justo después del de las llagas en sus manos, nos hace pensar que también es un mecanismo de destrucción de la cuarta pared para transmitir al espectador la sensación de extrañeza de lo onírico. Asimismo podría tomarse como la mirada interpelativa del cantante a su público, abandonando el rol de personaje para tomar el de artista. Ambas interpretaciones parecen correctas.

\section{Transtextualidad.}

Existen otros recursos externos a lo diegético que también colaboran a construir la ilusión narrativa. Por ejemplo, el establecimiento de similitudes con otros formatos típicamente narrativos como el cine hollywoodiense. En algunos de estos videoclips aparecen marcas textuales sobreimpresas en pantalla que les dotan de apariencia cinematográfica, sea un "the end" como en LIKE A PRAYER o una mención al autor del relato en que se basa el vídeo como en NOVEMBER RAIN. En este sentido THRILLER es el más fiel a las convenciones, ya que cuenta no sólo con el título, sino con todo tipo de textos que acompañan a una película: declaración de intenciones, el habitual mensaje de "todos los hechos aquí relatados son ficción” y una larga secuencia de créditos finales. Es TAKE ON ME el único que no posee este tipo de rótulos.

Otro asunto a destacar es cómo en estos videoclips se hace referencia a elementos externos al discurso musical y con una alta carga semántica, sea la iconografía religiosa en LIKE A PRAYER o las películas de terror en THRILLER. Según Mercer la canción "Thriller" desprende un halo de parodia que recoge el videoclip. Éste juega con los códigos y las convenciones del cine de terror, convirtiendo su relación con el tema en un diálogo intertextual (1993: 32-33). El gran éxito que había cosechado Un hombre lobo americano en Londres (1981) fue la inspiración para la creación de THRILLER, que contó con la realización de su mismo director, John Landis. La aparición de todo tipo de clichés, así como las referencias al cine de serie B de los años cincuenta o a las películas de George A. Romero hacen de este vídeo musical todo un homenaje al género. Vincent Price, otro grande del terror, aparece no sólo prestando su voz a la narración, que se inserta en la grabación original la canción, ya que su nombre puede verse en el cartel del cine que abandona la pareja.

En LIKE A PRAYER ocurre un cruce de referencias similar, sólo que aplicado a la iconografía del cristianismo. Según Freccero (1992: 168) la producción de Madonna se localiza dentro de 
la historia y la espiritualidad popular de la imaginación cultural italo-americana. Además es al parecer una especie de remake de un corto anterior de la realizadora, Mary Lambert, titulado Siesta(1987) que igualmente jugaba con los tópicos de lo latino (en este caso españoles) y la imaginación onírica (Feccero, 1992: 175).

En cuanto a la relación con el propio discurso musical, todos estos videoclips desarrollan un tema que estaba presente en la canción, pero aportando nuevos matices. Partiendo de unas letras ambiguas, centradas en los sentimientos (TAKE ON ME, NOVEMBER RAIN, LIKE A PRAYER) se ha elaborado una historia que en principio no estaba presente. En THRILLER, un tema que narra la experiencia de una noche viendo películas de terror con tu pareja, se ha dado a la situación una vuelta de tuerca para convertir el videoclip en una de esas películas de terror.

Por último, hemos de mencionar que la historia contada puede no finalizar dentro de un único vídeo musical, prolongándose la narración fuera de sus fronteras. Los personajes que aparecen en TAKE ON ME, vuelven a dejarse ver al comienzo del vídeo musical del siguiente single del grupo "The sun always shine on tv", donde el relato definitivamente termina ya que, coincidiendo con la introducción instrumental de la canción, vemos como el protagonista abandona a la chica para volver a su mundo de papel. Aquí se añade un "the end", también una referencia al cine clásico hollywoodiense pues posee la tipografía y el logo de las producciones clásicas de la Metro. El resto del videoclip continúa con imágenes del grupo actuando y no se vuelve a hacer referencia a lo que hemos visto durante su comienzo.

\section{Conclusión}

La forma que un videoclip tiene de contar una historia está determinada por la influencia que tanto la música como las convenciones musicales tienen en él. La estructura impuesta por las radio-fórmulas a la canción, los usos y costumbres de las actuaciones musicales retransmitidas por televisión o la necesidad de promocionar al cantante de un determinado modo son elementos sin los cuales el videoclip no poseería los rasgos que acostumbramos a encontrar en él.

Quizá el más llamativo de estos aspectos sea su naturaleza fragmentada. Esta fragmentación no sólo queda reflejada a nivel formal, donde se establece una clara separación entre los segmentos de actuación (performativos) y los narrativos. Encontramos otras rupturas dentro 
de la diégesis narrativa y también en la línea que separa el universo ficcional y el no ficcional, que se vuelve difusa. Si atendemos a lo que algunos autores han señalado, esta fragmentación múltiple estaría determinada concretamente por el sometimiento de la imagen a la estructura del tema musical, que se establece como un esquema previamente fijado e invariable (Goodwin, 1992: 64) (Vernallis, 2004: 17).

El videoclip se articula, de este modo, de forma similar al primer cine musical, donde la acción se paraliza al sonar la melodía para dar paso a una actuación (Mundy, 1999: 57). Así, THRILLER introduce la mayor parte del contenido narrativo fuera de los límites de la canción, dedicando el metraje ocupado por ésta a escenas de baile que se intercalan con algunas acciones (los muertos se alzan de la tumba, Michael se convierte en zombi). Los demás videoclips analizados no presentan esas secuencias de apertura y cierre no musicalizadas previas y posteriores a la recreación audiovisual de la canción o si aparecen, como en NOVEMBER RAIN, no son tan relevantes. Precisamente por ello están más fragmentados, puesto que la convivencia en el espacio limitado y de estructura definida de la canción de secuencias performativas y narrativas provoca que éstas hayan de alternarse según las imposiciones de la música. De este modo, un cambio brusco del ritmo en NOVEMBER RAIN introduce la sorprendente conclusión de la historia, la escena en que el ataúd de la novia entra en la iglesia donde previamente se había celebrado la boda. Igualmente, en TAKE ON ME el principal giro en el argumento se da en el puente instrumental, donde la imagen gana protagonismo y adopta, con mucha más facilidad que en las partes cantadas, de mayor carga semántica, el papel de banda sonora. De la misma manera, la conclusión de la historia coincide con las últimas estrofas de la canción, consistentes en la repetición de versos anteriores y, por tanto, información redundante. En LIKE A PRAYER, aunque el esquema es algo más complejo, el grueso de la acción narrativa se manifiesta al comienzo y al final del vídeo, incluyéndose el flashback de mayor duración hacia la mitad del metraje, sobre una repetición del estribillo y un puente musical. Es llamativo y destacable también que el sueño se constituya en tres de estos vídeos como la excusa para justificar esa fragmentación visual. Similar papel realiza el escape a un mundo ficticio en TAKE ON ME.

Otro rasgo destacado de los vídeos musicales analizados es la particular caracterización de los protagonistas de sus narraciones, que se sitúan en un terreno fronterizo entre lo performativo (la dimensión musical del personaje, su identidad "real") y lo narrativo (su dimensión ficcional). Como hemos visto, suelen establecerse enlaces entre el personaje y la persona real (Michael Jackson en THRILlER se llama Michael, la novia de Axl Rose en Admira $\mathrm{n}^{\mathrm{o}} 3-2011$ 
NOVEMBER RAIN era su pareja auténtica), lo que hace que el espectador iniciado en la mitología del ídolo en cuestión o en la cultura del pop identifique y enlace ambas dimensiones. De este modo, los vídeos musicales narrativos dan una nueva lectura a la canción, una interpretación que está relacionada con la intimidad (ficcional) del artista que la interpreta. Es decir, permite al espectador entrar en la vida privada de su ídolo sin que éste desvele su intimidad real. En este aspecto, el vídeo musical recoge el testigo de las películas musicales de Elvis, The Beatles o la serie televisiva The Monkees, que combinaban la interpretación de canciones con la narración de las aventuras y desventuras del artista en cuestión, todo un reclamo para el fan, ansioso de saber más sobre su cantante preferido y descubrir nuevas facetas suyas.

A pesar de que la gran mayoría de videoclips realizados no son narrativos, es innegable que muchas de sus muestras más representativas sí podrían calificarse como tales. A principios de los ochenta, Michael Jackson popularizó la tendencia de realizar un videoclip con valor añadido, narrativo en este caso, en BILLIE JEAN. Este modo de promoción se consolidó con THRILLER unos meses después. El enorme éxito obtenido por este último llevó a la imitación de sus eficientes mecanismos de publicidad. En este texto hemos realizado un análisis de alguno de los hitos más significativos de ese videoclip narrativo en una etapa en que la televisión musical, y en concreto la MTV, se encontraba en plena expansión, aunque aún no había aún cruzado las fronteras de los Estados Unidos. En la actualidad, donde el videoclip se consume casi tanto o más a través de Internet que en la televisión, su variedad narrativa es, si cabe, más popular que nunca. Los nuevos medios ofrecen mayor libertad creativa y, al no ser necesaria la inserción en un flujo de programación predeterminado, no existen límites de duración previos $\mathrm{u}$ otras imposiciones a las que sea obligatorio atenerse. Todo esto ha permitido que el añadido que significa introducir una diégesis en un vídeo musical sea un recurso más accesible que en el pasado. En 2010, por ejemplo, muchos son los artistas que han lanzado videoclip de carácter narrativo ${ }^{7}$. Esto demuestra la versatilidad de esta modalidad que, aunque no es la forma más habitual, sí se trata de una de las más características del vídeo musical y de las que mayor huella deja en la retina del espectador.

\section{Notas}

${ }^{1} \mathrm{Al}$ citar vídeos musicales, ya que parece no haber un criterio formal establecido, seguiremos el modo de hacerlo de Goodwin, que ya ha sido adoptado por otros autores (Selva, 2009). De este modo el nombre del videoclip aparecerá en versalitas (THRILLER), el nombre de la canción 
entrecomillado ("Thriller") y el de programas de televisión, películas, elepés o antologías en vídeo, en cursiva (Thriller).

${ }^{2}$ Por ejemplo, de la clasificación realizada por Saul Austerlitz (2007) "Top 100 video list”, casi la mitad de los treinta primeros clasificados son vídeos narrativos o con una fuerte presencia de los elementos narrativos.

${ }^{3}$ Los clásicos eros y thanatos.

${ }^{4}$ Quizá fue un intento de suavizar las explícitas implicaciones religiosas de la iconografía del vídeo y su relación con la personalidad real de la cantante. Cosa que sin duda no se consiguió, visto el revuelo que causó este videoclip entre algunos sectores (Freccero, 1992: 173).

${ }^{5}$ Es en THRILLER donde se produce la más explícita identificación del personaje con el artista: La chica lo llama "Michael”, estableciendo así un nexo inequívoco entre ambas facetas.

${ }^{6}$ Según Mercer, hay mucho más detrás de la recreación de la imagen de Michael Jackson en este videoclip. El artista posee una mitología especialmente rica construida por los medios. Ya en la fecha de lanzamiento de Thriller comenzaban a circular rumores sobre sus operaciones de cirugía, su síndrome de Peter Pan y su ambigüedad sexual (1993: 28). Su conversión en monstruo podría entenderse así como un paralelismo con las transmutaciones de ser humano a freak propiciada por la acción de los medios (1993: 41-42)

${ }^{7}$ Por ejemplo, (IT’s Not War) Just The End Of Love de Manic Street Preachers (Alex Smith), la serie de vídeos interrelacionados que comienza con NA NA NA de My Chemical Romance(Roboshobo y Gerard Way), LOVE THE WAY You LIE de Eminem y Rihanna (Joseph Kahn), Firework de Katy Perry (Dave Meyers), TelePhone de Lady Gaga (Jonas Akerlund), Born Free de M.I.A. (Romain Gavras), o The Suburbs de Arcade Fire (Spike Jonze), por sólo citar algunos.

\section{Referencias bibliográficas}

Austerlitz, S. (2007). Money for nothing: A story of the music video from the Beatles to the White Stripes. Nueva York: Continuum.

Beebe, R. \& Middleton, J. (editores) (2007). Medium cool: Music videos from Soundies to cellphones. Durham: Duke University Press.

Carlsson, S. (1999). Audiovisual poetry or Commercial Salad of Images en Musiikin suunta (The Direction of Music), 2/1999. Finnish Society for Ethnomusicology. Universidad de Helsinki. (www.zx.nu/musicvideo/musicvideo.pdf) (03-02-2011) 
Casetti F. \& Di chio F. (2007). Cómo analizar un film. Barcelona: Paidós.

Chatman, S. (1980). Story and discourse: Narrative structure in fiction and film. Ithaca y Londres: Cornell University Press.

Durá Grimalt, R. (1988). Los video-clips: Precedentes, orígenes y características. Valencia: Servicio de publicaciones de la Universidad Politécnica de Valencia.

Fiske, J. (1989). Reading the popular. Nueva York y Londres: Unwin Hyman.

Fiske, J. (1986). MTV: Post-structural post-modern en Journal of communication inquiry, vol.10, $\mathrm{n}^{\mathrm{o}} 1 ; 74-79$.

Freccero, C. (1992). Our Lady of MTV: Madonna's 'Like a Prayer' en Boundary 2, vol. 19, $\mathrm{n}^{\circ} 2$, Feminism and Postmodernism; 163-183. Londres: Duke University Press.

Genette, G. (1998). Nuevo discurso del relato. Madrid: Cátedra.

Genette, G. (1989). Palimpsestos: La literatura en segundo grado. Madrid: Taurus.

Goodwin, A. (1992). Dancing in the distraction factory: Music television and popular culture. Minneapolis: University of Minnesota Press.

Kaplan, E. A. (1987). Rocking around the clock: music television, postmodernism, and consumer culture. Nueva York: Methuen.

Mundy, J. (1999). Popular Music on Screen. From Hollywood Music to Music Video. Manchester: Manchester University Press.

Mercer, K. (1993). Monsters metaphors: notes on Michael Jackson's Thriller en Frith, Simon; Goodwin, Andrew y Grossberg, Lawrence (Eds.). Sound and Vision: The music video reader. Londres: Routledge; 93-108.

Sedeño Valdellós, A. (2002). Lenguaje del videoclip. Málaga: Servicios de Publicaciones e Intercambio Científico de la Universidad de Málaga.

Selva Ruiz, D. (2009). El videoclip como herramienta de comunicación comercial del sector fonográfico. Tesis doctoral. Universidad de Sevilla.

Vernallis, C. (2004). Experiencing Music Video: Aesthetics and Cultural Context. Nueva York: Columbia University Press.

Viñuela Suárez, E. (2009). El videoclip en España (1980 1995). Gesto audiovisual, discurso y mercado. Madrid: Instituto Complutense de Ciencias Musicales. 